\title{
Maxwell Alexandre: as cores estão no mundo
}

\author{
Maxwell Alexandre: The colors are in the World \\ Maxwell Alexandre: los colores están en el mundo
}

\author{
Marcelo Campos ${ }^{1}$ \\ Juliana Pereira 2
}

\begin{abstract}
1 Professor Associado do Departamento de Teoria e História da Arte do PPGArtes e do PPGHA do Instituto de Artes da UERJ. Curador chefe do MAR. Lattes: http:// lattes.cnpq.br/4042663622905586; ORCID: https://orcid.org/0000-0001-60115318. e-mail: marcelo.campos@uerj.br

2 Mestranda (PPGHA/UERJ) na linha de arte e alteridade. Lattes: http://lattes. cnpq.br/0002016125482049; ORCID: https://orcid.org/0000-0002-9236-6098. e-mail: julianaper@gmail.com
\end{abstract}




\section{Revista Apotheke}

\section{Resumo}

Maxwell Alexandre nasceu, vive e trabalha no Rio de Janeiro, morador da Rocinha, uma das maiores favelas da América Latina. Este texto procura discutir a relação das pinturas de Maxwell Alexandre, a partir de suas relações com as cores. Parte desse interesse se dá por conta de uma das séries do artista, denominada, "Pardo é papel". Maxwell apresenta uma exposição homônima em Lyon, no Rio de Janeiro e em Porto Alegre. Em poucos anos de produção, o pintor se torna uma das grandes referências para a arte brasileira e, sobretudo, participa da cena de jovens artistas afrodescendentes. Relações etnicoraciais, empoderamento do povo preto, universo da música hip hop, são muitas as conexões possíveis entre a produção de Maxwell Alexandre e a recente produção das artes, da música e da sociedade com os marcadores sociais de raça e classe. A cor se apresenta em diálogo com elementos da publicidade e das instituições normatizadoras, como a polícia civil e a escola pública, tanto quanto com a bandeira do Rio de Janeiro. De outro modo, o artigo procura problematizar as teorias raciais e a possibilidade de um artista afrodescendente em lidar com um elemento, a cor, tão relacionado a um sistema de arte racista e excludente.

\section{Palavras-chave}

Maxwell Alexandre; arte contemporânea; empoderamento; relações etnicoraciais; cor.

\section{Abstract}

Maxwell Alexandre was born, lives, and works in Rio de Janeiro, a resident of Rocinha, one of the biggest slums of Latin America. This paper pursues the relation of Maxwell Alexandre's paintings, from his relationship with the colors. Part of that concernment is due to one of the artist' series called "Pardo é paper". Maxwell presents a homonym exhibition in Lyon, Rio de Janeiro, and Porto Alegre. In a few years of production, the artist turns one of the most important references to Brazilian art and, mainly, makes part in the young Afro-descendant scene of art. Ethnic racial relations, black people empowerment, hip hop music universe, there are many possible connections between Maxwell Alexandre's production and the recent production of the art, music, and society with the markers of race and class. The color dialogues with publicity elements and regulatory institutions, as the city police and the public school, as well as the Rio de Janeiro's flag. In another way, the paper pursues to discuss the racial theories and the possibility of an Afro-descendant artist to deal with an element, the color, so related to a racist and excluding art system.

\section{Key words}

Maxwell Alexandre; contemporary art; empowerment; etnico racial relations; color.

\section{Resumen}

Maxwell Alexandre nació, vive y trabaja en Río de Janeiro, residente de Rocinha, uno de los barrios marginales más grandes de América Latina. Este texto busca discutir la relación entre las pinturas de Maxwell Alexandre, a partir de su relación con los colores. Parte de este interés se debe a una de las series del artista, llamada "Pardo é papel". Maxwell presenta una exposición homónima en Lyon, Río de Janeiro y Porto Alegre. En pocos años de producción, el pintor se convierte en uno de los grandes referentes del arte brasileño y, sobre todo, participa en la escena de jóvenes artistas afrodescendientes. Relaciones étnicas, empoderamiento de la gente negra, el universo de la música hip hop, hay muchas conexiones posibles entre la producción de Maxwell Alexandre y la producción reciente de las artes, la música y la sociedad con los marcadores sociales de raza y clase. El color se presenta en diálogo con elementos de la publicidad y las instituciones reguladoras, como la policía civil y las escuelas públicas, así como con la bandera de Río de Janeiro. De lo contrario, el artículo busca problematizar las teorías raciales y la posibilidad de que un artista afrodescendiente se enfrente a un elemento, el color, tan relacionado con un sistema artístico racista y excluyente.

\section{Palabras-Clave}

Maxwell Alexandre; arte contemporáneo; empoderamiento; relaciones étnico-raciales; color

ISSN: 2447-1267 
Em 1968, Paulinho da Viola gravou "Coisas do mundo, minha nega". Um samba em que a vontade do sambista em observar e comentar o mundo e suas vicissitudes era imensa. A tudo, cabia um samba. E, a todo instante, ele dizia à sua nega ao que veio: "hoje eu vim, minha nega, como venho quando posso, na boca as mesmas palavras, no peito o mesmo remorso (...)". Em seguida, a cada estrofe, situações sociais em que o sambista encontra uma cena a ser transformada em samba: a doença, a pobreza, o desamor, o alcoolismo, a morte, a briga. Escrever sobre a cor na produção de Maxwell Alexandre, artista carioca, oriundo da Rocinha, também é observar o mundo. E fizemos a pergunta a ele, "como você lida com as cores"? A resposta nos coloca diante desta mesma sensação de observação do mundo, como no samba de Paulinho da Viola. Ele nos diz: "Tu usa o que tu tem" (...) "Uso muito o azul, por conta da bandeira do estado (do Rio de Janeiro), da camisa da escola pública, do carro da polícia, o rosa do Danone" (informação verbal) ${ }^{1}$. Ou seja, as coisas estão no mundo, as cores estão no mundo, como na frase do samba. Mas em que mundo vivemos? "Acho que o lugar que tem mais conceito da cor no meu trabalho, acho que é o pardo, da série "pardo é papel".", afirma Maxwell.

Dentre toda a produção artística de Maxwell Alexandre, as mais populares e impressionantes são as gigantescas pinturas feitas sobre papel pardo. A escolha desse suporte não é apenas uma opção estética, existe um discurso racial por trás dessa decisão. "Pardo é papel" é o nome de uma de suas exposições, que já passou pelo Museu de Arte do Rio e pela Fundação Iberê Camargo. "Pardo é papel" também é uma frase usada popularmente para recusar a ideia de pardo como categoria de cor/ raça: " "pardo é papel", [não cor de gente]". Os movimentos negros rejeitam o termo pardo e recomendam que se use "negra/o de pele clara", já que o termo pardo também se refere a pessoas racializadas, e o tom de pele mais claro, não as salva dos efeitos nefastos do racismo. Juntos, os autodeclarados negras/os ou pardas/os representam em média $56 \%$ da população brasileira² .

\footnotetext{
"A série já começa sobre o pardo do papel. Não tem borracha. O que fiz foi preparar uma tinta da cor do papel pardo para apagar o que eu não estava curtindo. Nesse período, peguei umas pinturas abstratas que não gostava muito. Aí eu comecei a cobrir com a cor parda essas pinturas. Um amigo chegou e disse, você está criando máscaras. Nesse momento, o desígnio pardo se afirmou para mim como um desígnio de mascarar alguma coisa. O pardo para mascarar, o pardo para esconder." (Maxwell Alexandre, 2021)
}

Entendendo a denominação "pardo" como uma estratégia para enfraquecer a identidade racial da comunidade negra, Maxwell representa todas/os as/os personagens - sempre pessoas pretas - como retintas/os. Beyoncé, por exemplo, uma mulher negra de pele clara e uma artista de grande destaque no cenário mundial

1 Entrevista concedida por Maxwell Alexandre. [mar 2021]. Entrevistador: Marcelo Campos. Rio de Janeiro, 2021. mensagem de áudio (12 '33").

2 GERALDO, N. Quase brancos, quase pretos. Após longa discussão histórica, pardo ganha nova identidade: negro de pele clara. Universa. Uol. Disponível em: <https://www.uol.com.br/universa/reportagens-especiais/ quase-brancos-quase-pretos/\#page2>. Acesso em 6 mar. 2021. 
da cultura afro-americana que, por vezes, já teve sua negritude questionada, aparece em sua obra com o tom de pele bem escuro, deste modo, o artista garante que não restem dúvidas quanto a sua racialidade. Isso é algo que também tem relação com a materialidade, pois o artista costuma utilizar materiais como graxa ou henê (um produto de tom bem escuro, muito utilizado nas décadas de 80 e 90 para alisar os cabelos crespos) que não permitem produzir uma paleta de tons variados.

Com isso, a cor parda aparece como marca inescapável, difícil de se apagar. Contudo, as atitudes racistas no Brasil que preferem, algumas vezes, velar as ascendências raciais insistem em atribuir ao "pardo" um padrão para, nas palavras de Maxwell, uma "confidência de informação", como acontece com os envelopes pardos das correspondências: "eu lembrei do envelope de correspondência, mais uma vez encontrei esse desígnio pardo como [mecanismo para] você tirar a identidade, esconder alguma coisa." O artista nos conta que a relação entre a cor e a raça, como em uma descoberta do que você nem sabia que estava procurando, ao que se denomina "serendipidade/serendipty", faz com que ele passe a se dedicar intensamente a tal observação: "Eu comecei a pegar papel pardo para envelopar objetos, envelopei minha casa inteira. E nesse ambiente, onde tudo era pardo, eu vi que o pardo padronizava a identidade dos objetos." Maxwell, então, chama a série de "Confidência", pois a ideia do envelope pardo era a de tornar algo confidencial, como na tentativa de branqueamento, em que a atribuição da cor parda guardava certa esperança de apagar a miscigenação do Brasil, tornando o preto em pardo, como numa área intermediária, na esperança de seguir até branqueá-lo.

A tentativa de branqueamento, de outro modo, passou por cientificismos, por mecanismos supostamente racionais, explicados e retratados em gráficos e pirâmides, como na estratificação usada por teóricos do "darwinismo racial" que, segundo Lilia Schwarcz, "fizeram dos atributos externos e fenotípicos elementos essenciais, definidores de moralidades e do devir dos povos" (Schwarcz: 2012: p. 20). A branquitude, com isso, como nos explicam a própria Schwarcz e Gayatari Spivak, "é sempre uma alusão, quase uma benção" (Schwarcz: 2012, p. 11), ou, nas palavras da teórica indiana, uma transparência. Assim, percebemos que Maxwell Alexandre faz da cor parda a "borracha", uma borracha que não elimina, não apaga, mas mancha, produzindo uma correção que é, ao mesmo tempo, uma afirmação: "pardo é papel", desaparecendo, de vez, com outras alusões muito comuns na arte, na literatura, no cinema, de que partimos, na criação, de uma ideia, de um enfrentamento com o branco do papel, da tela, da folha. Na série de MW, parte-se do pardo e as supostas correções são revertidas em apagamentos. Enfrenta-se, com isso, uma afirmação de que as manchas destacadas funcionam como a já citada estratégia de manter pessoas "pardas" mais "pretas", para que as mesmas não desapareçam na cor de fundo do papel, fazendo, enfim, a dualidade branco e preto se intensificar e retornar como consciência.

W. E. B. Du Bois, teórico fundamental para os movimentos negros do século XX, escreverá, em 1910, o livro "As almas do povo negro", em que o autor, nascido em um século XIX ainda escravocrata, denuncia o racismo e elabora as lutas para que 
um único corpo congregue duas almas, a do povo preto e a do branco. Ao relatar sua passagem pela Universidade de Fisk, Du Bois afirma, "vi discriminação como jamais havia sonhado", separação nos vagões ferroviários, alojamentos, "o insulto no contato das raças nos lugares públicos" (Du Bois apud Costa: 1998: p. 7). O autor também terá a emblemática afirmação, em um discurso em Londres, em 1900, que o grande problema do século XX que, então, se iniciava, era a "linha de cor" que separava brancos e pretos. Observar um pintor, como Maxwell Alexandre, ainda tratar deste sintoma nos coloca em renovado dilema: até quando artistas pretas/os terão que tratar da urgência em eliminar uma política racista? $\bigcirc$ que vemos nas pinturas de Maxwell Alexandre não mais se liga a uma separação declarada, escrita em placas, como "colored people", mas, antes, a uma separação que não se desfez. Personagens pretas/os e pardas/os se misturam e são maioria nas pinturas do artista. Assim, vemos posições de enfrentamento e orgulho nas cores das roupas de marcas, caras e famosas, ou em grupos que se vestem todos de branco, como se pertencessem a uma banda musical, assemelhada às Supremes, grupo surgido em 1959, constituído por mulheres pretas que se vestiam iguais e ostentavam, nas roupas, brilhos, cores africanas ou, muitas vezes, se apresentavam vestidas de branco. Todos somos coloridos, por Maxwell, e enfrentamos as agruras de exibir e confrontar outras cores, em uma tentativa de sair da categorização parda, uma denominação que não escolhemos, mas que nos foi imposta. As cores em Maxwell, para além do pardo e preto da pele, se direcionam aos azuis, sobretudo, dos uniformes escolares e policiais. $\bigcirc$ que pode acontecer na alma do povo preto ao encarar o azul da farda da polícia civil do Rio de Janeiro? Se criados em ambiente familiar, o eco das palavras sobrevém: não corra, ande com a identidade no bolso, não tire a camisa da escola, entre tantos outros aconselhamentos das mães, avós, tias. Por outro lado, o colorido das roupas africanas, das batas, djellabas, torsos que tomam as ruas, presentes na câmara de deputados no século XXI, ainda incomoda a branquitude, quando ostentados por mulheres (trans e cis) pretas no exercício de seus mandatos, tal qual acontecera com Marielle Franco, assassinada em 14 de março de 2018 e, recentemente, com a primeira vereadora negra de Curitiba, Carol Dartora. O crime contra Marielle ainda está sem elucidação sobre quem a mandou matar. Marielle Franco é, muitas vezes, retratada nas pinturas de Maxwell Alexandre.

Nas palavras do professor Kabengele Munanga (2018, p.113) "definir as artes plásticas afro-brasileiras não é uma questão meramente semântica" por envolver uma complexidade de outras questões, como a história dos ancestrais escravizados no Brasil; a condição social do povo preto, na base da pirâmide e a cosmovisão dos povos vindos de África em contexto diaspórico. Porém, a arte afro-brasileira nasce do culto religioso e ritual de matriz africana. As primeiras manifestações dessa categoria artística são peças de culto e adoração aos Orixás africanos produzidas por artesãos relegados ao anonimato. Tais peças foram analisadas por teóricos, como, Nina Rodrigues ${ }^{3}$ que as incluíam em capítulos sobre as "sobrevivências africanas: as

3 Nina Rodrigues foi um dos primeiros autores a descrever práticas religiosas nos terreiros baianos. Esteve em pesquisa de campo nos candomblés em fins do século XIX e publicava os resultados de suas pesquisas em jornais 
línguas e as belas artes nos colonos pretos".

As proposições artísticas de Maxwell Alexandre também possuem uma proximidade com manifestações religiosas, porém, desta vez, refletindo o processo de evangelização em massa de pessoas negras que ocorreu e ocorre no Brasil. Dados estatísticos mostram que pretas/os e pardas/os compõem 59\% dos fiéis evangélicos do país ${ }^{4}$. Além disso, é visível que a distribuição de igrejas evangélicas no território das cidades segue uma razão econômica, ou seja, quanto mais pobre for a região (subúrbios e favelas), maior é a ocupação por parte de igrejas evangélicas, da mesma forma, a concentração de pessoas negras aumenta consideravelmente nas regiões mais pobres, já que, no Brasil, "raça é uma fundamental categoria de classe" (ASANTE apud NASCIMENTO, 2019, p. 38). Maxwell Alexandre é cria da Rocinha e nasceu em berço evangélico. Na maioria de suas obras está presente o padrão das tradicionais piscinas de plástico que, além de muito utilizadas para o lazer nas casas do subúrbio e comunidades, também são vistas com frequência em igrejas evangélicas, principalmente as mais humildes, para o batismo dos fiéis. $\bigcirc$ batismo significa renascer em Cristo, ser lavado dos pecados, é uma demonstração pública de aceitação de Jesus como seu salvador. "Quem crer e for batizado será salvo; mas quem não crer, será condenado" (Marcos 16:16). Estando assim escrito na Bíblia, para os evangélicos de todas as denominações, o batismo é um mandamento que deve ser seguido por todas as pessoas que desejam ser arrebatadas no dia do juízo final.

De outro modo, nas pinturas de Maxwell Alexandre, as cores que prevalecem e são, muitas vezes, sublinhadas, são as cores do consumo, das coisas que estão no mundo, mas que nem sempre são acessíveis ao povo preto. Com isso, o rosa do Danone, o marrom do Todinho, o ouro e a prata das joias, ostentadas por rappers, carros, aviões, celulares, óculos de sol ganham destaque em cores abertas, fluorescentes, cintilantes. A citada predominância dos azuis das piscinas de plástico e nas caixas d'água também se liga à recorrência da diversão e da vida nas lajes e quintais das favelas e dos subúrbios. A trajetória do artista, ocupando lugares de destaque em galerias e museus, levando um público que, em muitos casos, jamais entrara em um museu, ou, mesmo, sendo o primeiro artista preto a ter uma individual em museus, como, a Fundação Iberê Camargo, faz com que a própria iniciativa, mesmo antes das obras, altere e desfaça, ainda que não resolva, a "linha de cor", nos termos de Du Bois, que marcava o sistema da arte.

Maxwell Alexandre faz parte de uma safra de artistas que surge em consonância com uma nova onda do movimento negro no Brasil, impulsionada por um discurso que não é novo, no entanto, chega com fôlego renovado, muito fortalecido pelas redes sociais e mídias digitais, atingindo um grande alcance e forçando reflexos

e livros. Como médico legista, apresentava forte teor racista e eugenista em suas análises. Contudo, desde os anos 1930, quando teve seus estudos relançados, tornou-se fonte de consulta sobre nomes, lugares, práticas e terreiros que se mantém até a atualidade. Destacou a produção artística encontrada nos terreiros.

4 ROMANO, G. Datafolha: Mulheres e negros compõem maioria de evangélicos e católicos. Público feminino corresponde a $58 \%$ dos frequentadores de igrejas evangélicas e $51 \%$ de católicas; pretos e pardos são 59\% e 55\% dos fiéis, respectivamente. 13 jan 2020. Veja. Abril. Disponível em: <https://veja.abril.com.br/religiao/datafolhamulheres-e-negros-compoem-maioria-de-evangelicos-e-catolicos/>. Acesso em 6 mar 2021. 
nas programações de instituições dos mais diversos campos, como por exemplo a tradução de intelectuais negras/os falantes de outros idiomas, para atender demandadas como, lugar de fala, diversidade cultural, representatividade, etc. As pinturas de Maxwell profetizam uma ascensão do povo negro, como na obra "Éramos as cinzas e agora somos o fogo", cujo nome foi extraído dos versos do rapper BK. Uma pintura de grande escala onde vemos pessoas negras sendo representadas no centro da narrativa, em uma posição ativa em relação às suas próprias vidas. Um grupo de formandos ao centro, em primeiro plano, uma pessoa ergue "o canudo" (diploma) e uma mulher negra usa roupas brancas, mas não está em serviço como babá, ela embala seu próprio bebê protegida por outra mulher, que obstrui a violência policial com seu próprio corpo, com um facão em punho. Arthur Bispo do Rosário, um ancestral negro da arte afro-brasileira, aparece vestindo seu Manto da apresentação. Com esse gesto, o artista problematiza e desconstrói uma série de imagens de controle ${ }^{5}$, o que poderá gerar, como efeito, o empoderamento da sua própria comunidade, a exemplo de Abdias Nascimento.

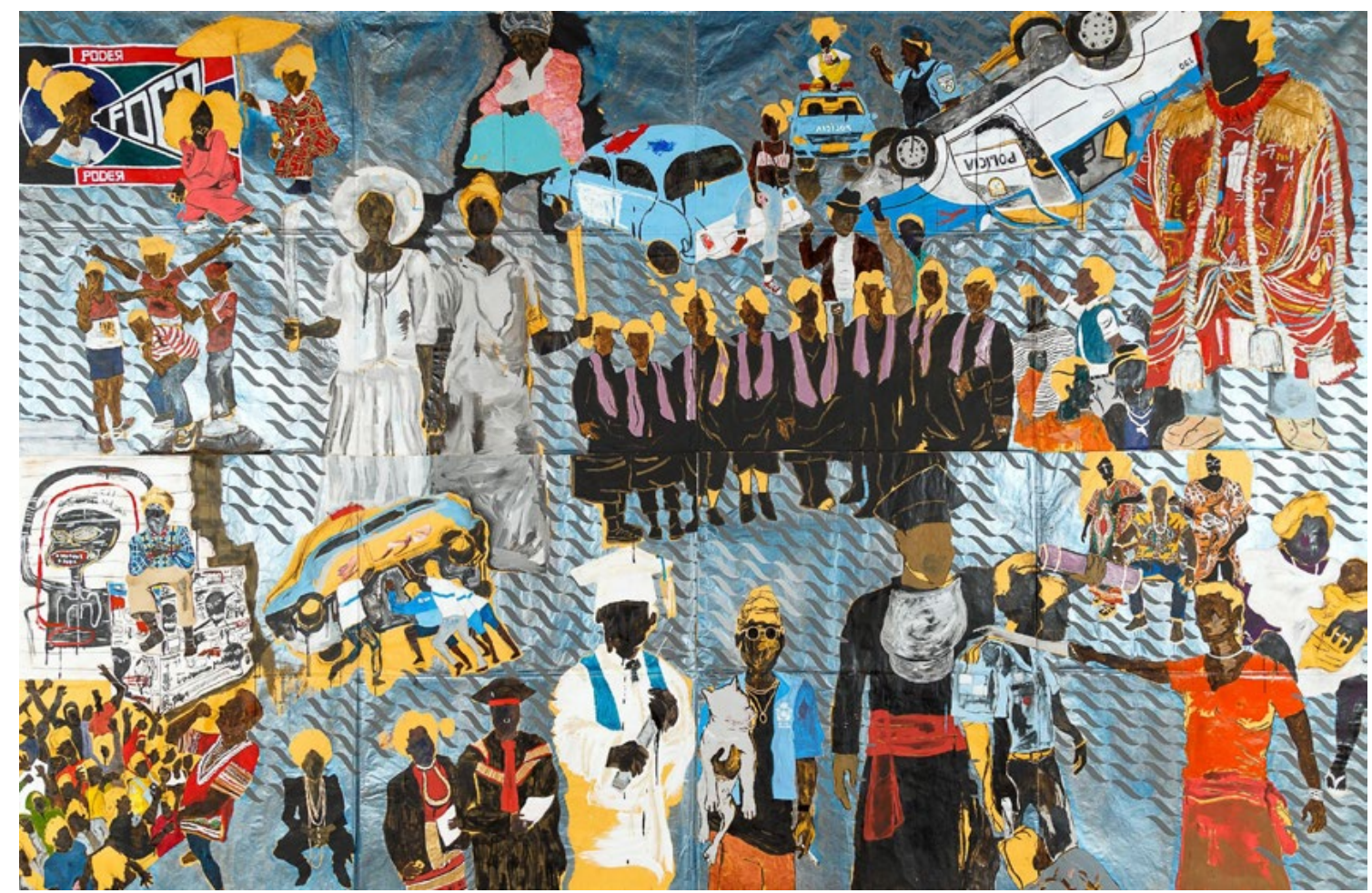

Fig. 1, Maxwell Alexandre, Éramos cinzas e agora somos o fogo (diss), da série Pardo é Papel, 2019. Látex, graxa, henê, betume, corante acrílica, vinílica, grafite, carvão e bastão oleoso sobre papel pardo, $360 \times 736 \mathrm{~cm}$, Coleção do Artista.

Ativista do Pan-africanismo e um homem extremamente preocupado com a autoestima do sujeito negro, Abdias fundou diversas iniciativas que tinham como objetivo fortalecer o espírito dos seus pares, dentre elas o Teatro Experimental do Negro (TEN) e o Museu de Arte Negra (MAN), ansiava em construir condições para que pessoas negras pudessem se sentir contempladas e devidamente representadas. Ainda com esse objetivo, lançou, em 1955, por sugestão de Guerreiro Ramos, um 
concurso de artes plásticas acerca do tema "Cristo Negro", com a intenção de "promover um reexame da concepção estética brasileira" (NASCIMENTO, 2019, p.132). Apesar de ter sido duramente criticado e atacado pela classe dominante, majoritariamente branca, deste país por seu feito, este foi um gesto absolutamente consciente, uma manifestação contrária ao culto a um Cristo forjadamente branco em um país majoritariamente preto.

Maxwell, menino criado sob os preceitos cristãos, também pinta seu Cristo negro, em uma pintura intitulada "A vitória gloriosa", onde um menino negro de cabelos descoloridos (loiro pivete), vestindo uma bermuda que pertence ao uniforme das escolas municipais do Rio de Janeiro, aparece ao centro sendo saudado pelos mascotes do Toddynho e do Danoninho, em uma pose que remete à imagem do Cristo crucificado. Esta representação nos leva a refletir sobre as verdadeiras origens de Jesus, certamente um menino negro, refugiado, perseguido e inocente, porém condenado a morte por uma sociedade opressiva e conservadora. A experiência vivida por Jesus, em sua passagem pela Terra, se assemelha à vivência e ao cotidiano de milhares meninos negros das periferias e favelas.

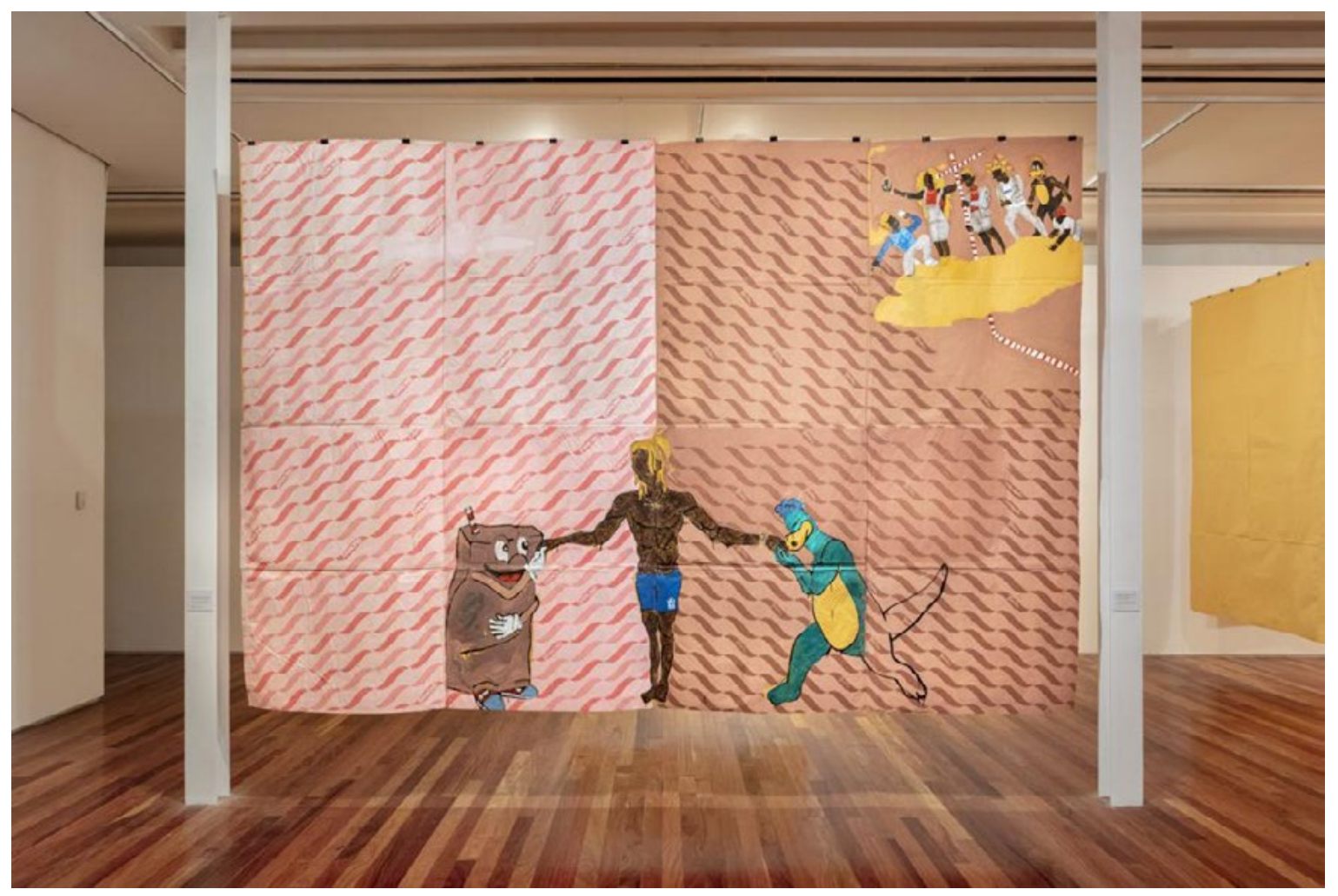

Fig. 2, Maxwell Alexandre, A vitória gloriosa, da série Pardo é Papel, 2018. Látex, graxa, henê, betume, acrílica, grafite, carvão e bastão oleoso sobre papel pardo, $320 \times 476 \mathrm{~cm}$, Fortes D'aloia e Gabriel, Rio de Janeiro e São Paulo. A Gentil Carioca, Rio de Janeiro.

Brancos e pretos no Brasil, esta é uma dualidade mascarada por centenas de denominações para a cor da pele que permanece como subterfúgio para o racismo estrutural, cotidiano, psicologicamente traumático que leva uma parte significativa da população afrobrasileira à morte. Maxwell Alexandre traça uma trajetória, na arte e na 
vida, em que comenta e se posiciona diante de uma sociedade, na qual o capitalismo atravessa o sistema de consumo e se refestela no sistema da arte, naturalizando as paredes brancas dos museus e galerias, metaforizando o "branco" das telas e papéis como início dos processos de criação, enquanto o mesmo sistema se cala diante do baixo quantitativo de artistas, curadores, gestores, galeristas pretos e pretas.

A arte de Maxwell Alexandre atravessa uma cidade, fazendo da ficção, um antídoto de consciência e uma reflexividade de cura aos traumas coloniais que marcam os pretos e pardos, mas que permanecem marcando outras cores na visualidade metropolitana. Nas obras de MW, vemos como as cores podem, concomitantemente, ganhar subjetividades opressoras e orgiásticas, orgulhosas e nefastas, como os azuis das fardas, uniformes e das piscinas.

Se a crença na ciência não funcionou para mostrar o absurdo de um dos maiores males da sociedade, o racismo, a arte, em pleno uso da ficção, têm escancarado o mundo em que vivemos.

* As imagens utilizadas neste artigo, bem como a autorização de uso, foram cedidas pelo artista.

\section{Referências}

COLLINS, Patricia. Pensamento Feminista Negro: Conhecimento, consciência e a política do empoderamento. Tradução de Jamille Pinheiro Dias. 1. ed. São Paulo. Boitempo, 2019.

DU BOIS, W. E. B. As almas do povo negro. (Tradução José Luiz Pereira da Costa). Disponível em: https://afrocentricidade.files.wordpress.com/2016/04/as-almas-do-povo-negro-w-e-bdu-bois.pdf

NASCIMENTO, Abdias. O Quilombismo: Documentos de uma Militância Pan-Africanista. 3. ed. rev. São Paulo. Editora Perspectiva. Rio de Janeiro. Ipeafro, 2019.

MUNANGA, Kabengele. Arte afro-brasileira: $O$ que é, afinal? In: PEDROSA, Adriano; CARNEIRO, Amanda; MESQUITA, André. Histórias Afro-Atlânticas. V. 2. Antologia. São Paulo. MASP. 2018. p. 113-123.

SCHWARCZ, Lilia. Nem preto nem branco, muito pelo contrário: cor e raça na sociabilidade brasileira. São Paulo: Claro enigma, 2012.

Submissão: 15/03/2021

Aprovação: 30/03/2021 